\title{
HISTORIA DE LA CODIFICACIÓN DEL DERECHO CIVIL EN HUNGRÍA*
}

\author{
HISTORY OF THE CODIFICATION OF CIVIL LAW IN HUNGARY
}

Gábor Hamza*

\begin{abstract}
Resumen:
Este artículo trata el desarrollo histórico de la codificación del Derecho Privado húngaro, principalmente del Derecho civil. Muestra no solo la influencia inicial mixta del Derecho romano y de la Pandectística alemana, sino también su apertura posterior y paulatina a otros sistemas jurídicos. Los recurrentes fracasos de la codificación tuvieron principalmente razones coyunturales políticas y económicas. El actual Derecho privado, con el ingreso de Hungría a la U.E. ha recibido las influencias contemporáneas en su conformación.

Palabras clave: Codificación civil húngara. Proyectos de Código Civil húngaro. Código Civil húngaro. Influencias en la codificación húngara.

Abstract:

This article is about the historical development of the codification of Hungarian Private Law, mainly Civil Law. It shows not only the initial mixed influence of the Roman Law and the German Pandectists, but also their subsequent and gradual opening to other legal systems. The recurrent failures of this codification have had contextual political and economic reasons. Current private Law, due to the entry of Hungary into the European Union, has received the contemporary influences in its design.
\end{abstract}

Keywords: Hungarian civil codification. Hungarian Civil Law Projects. Hungarian Civil. Code. Influences in the Hungarian codification.

1. Como introducción a un panorama general sobre la codificación en Hungría, se debe aclarar que la vida jurídica de ese país experimentó un cambio radical por influencia de la Escuela Histórica del Derecho (en alemán: "Historische Rechtsschule") alemana. Este punto de inflexión se manifestó inicialmente a través del primer gran jurista de Derecho privado del siglo XIX, Ignác Frank (1788-1850), quien se mostró, como Friedrich Carl von Savigny (1779-1861), consecuentemente contra la codificación del Derecho privado. El encomiable jurista húngaro László Szalay (1813-1864) describe a su contemporáneo Ignác Frank como el "guía de una nueva era”. Frank, en su obra publicada en 1823 y titulada Specimen elaborandarum institutionum iuris civilis Hungarici, aplicó conceptos del Derecho romano a los efectos de explicar las relaciones reales sobre inmuebles en Hungría, los que también aparecen en otros trabajos. Un comprometido

\footnotetext{
* Traducción desde el alemán de Alvaro Pérez Ragone.

** Catedrático de Derecho Romano de la Facultad de Derecho de la Universidad Eötvös Loránd de Budapest. Miembro de la Academia de Ciencias Húngara. Dirección postal: ELTE Római Jogi Tanszék, Egyetem tér 1-3, H-1053 Budapest, Hungría. Correo electrónico: gabor.hamza@ajk.elte.hu.
} 
adherente de la Escuela Histórica del Derecho fue también Ignác Frank, discípulo de Gusztáv Wenzel (1818-1891), en cuya obra es posible encontrar de todas maneras un gran número de referencias al Derecho romano.

Es a partir de la mitad del siglo XIX cuando la Pandectística alemana o la Ciencia de las Pandectas comienza a ejercer una importante y creciente influencia en las Ciencia jurídica y en la práctica judicial húngara. La mayoría de los romanistas y iusprivatistas húngaros fueron discípulos de los pandectistas alemanes. El más renombrado discípulo húngaro de Jhering fue el romanista y iusprivatista Gusztáv SzászySchwarz (1858-1920). Mihály Biermann (1848-1889) - que perteneció a la Academia de Derecho (en alemán: "Rechtsakademie", en húngaro: "jogakadémia") en Győr y más tarde en Nagyszeben (en alemán: Hermannstadt, actualmente Sibiu en Rumania) - asistió a las clases de Rudolf von Jhering en Göttingen. El gran jurista especialista en Derecho comparado e internacionalmente reconocido Elemér Balogh (1881-1953) fue discípulo de Heinrich Dernburg (1829-1907) en Berlín. A través de su actividad literaria, estos y otros juristas húngaros impulsaron la recepción de elementos de la pandectística alemana en la jurisprudencia (ciencia jurídica) húngara.

Luego del fracaso de la codificación del Derecho privado es que comenzó el intento del hegeliano y decisivo opositor de las ideas escépticas sobre la codificación de Savigny, László Szalay (1813-1864), para codificar el Derecho privado húngaro sobre los fundamentos del Code Civil francés, considerado por aquel como la máxima expresión de la codificación. Este intento, sin embargo, estaba condenado al fracaso, ya que el Code Civil francés como modelo de un Código Civil no era aceptable en la Hungría de entonces, ante todo por razones políticas e ideológicas.

Se debe resaltar que en la época de las reformas, numerosos sectores del Derecho privado en sentido amplio habían sido objeto de regulación legal en el reino de Hungría, por ejemplo, en el Derecho comercial y en el concursal.

2. A impulso de la Revolución y la Guerra por la Independencia en 1848/1849, se promulgó la ley 1848: XV, que fundamentalmente tuvo por objeto derogar la que regulaba el Derecho sucesorio feudal (en alemán: “Avitizität" - en latín: aviticitas) y anunciar la codificación del Derecho privado.

A los efectos de preparar la codificación, el entonces renombrado jurista y por entonces ministro de justicia Ferenc Deák (1803-1876) erigió en el "Ministerio de Justicia" (entiéndase por tal una sección del por entonces Ministerio único) un área dedicada a la codificación. Deák fijó como tareas, entre otras, la redacción de los “códigos penal, civil y de minería". Inicialmente se encargó la dirección de dicha sección al propio László Szalay, como lo aclara una carta de Szalay enviada desde Frankfurt am Main (donde él, en aquel entonces, formaba parte de una misión diplomática alemana para la Asamblea Nacional). Szalay no pudo entregar el proyecto a la Asamblea Nacional húngara 
convocada el 2 de julio de 1848. Un reducido expediente es lo único que se encontraba en el material de archivo del "Ministerio de Justicia".

La consecuencia fue el fracaso de este tercer intento de codificación, ante todo por los posteriores sucesos históricos (el fracaso del movimiento independentista húngaro).

3. Luego de la derrota en la Guerra por la Independencia en agosto de 1849, en el año 1853 en Hungría (y varios meses después, el 1 de septiembre de 1853, también en Siebenbürgen) entró en vigencia por disposición real el Código Civil General austriaco (Allgemeines Bürgerliches Gesetzbuch" - ABGB.). El reestablecimiento del constitucionalismo es decir del sistema constitucional en la Hungría monárquica se realizó a través del "Oktoberdiplom” en el año 1860, que se puede equiparar a una constitución política. De acuerdo con lo dispuesto en el Oktoberdiplom, la competencia legislativa para la codificación del sistema jurídico quedó reservada a la Dieta o al Consejo Real. Como consecuencia, se convocó a una conferencia de Asamblea de Justicia (en alemán: "Iudexcurialkonferenz", en húngaro: “Országbírói Értekezlet”) en Sopron (ciudad designada en lengua alemana como Ödenburg), conferencia que tomó la iniciativa de llevar adelante la reforma del Derecho privado húngaro con bases nacionales.

Uno de los miembros de esta Conferencia de Justicia fue, entre otros, György Zsivora (1804-1883), ${ }^{1}$ partidario del mantenimiento del Código Civil General austriaco, aunque con algunas modificaciones. Estas modificaciones deberían contemplar las características particulares del desarrollo jurídico húngaro.

En el año 1861, la Conferencia de Justicia emitió las Reglas Provisorias de la Justicia (en húngaro: “Ideiglenes Törvénykezési Szabályok”). Hasta la promulgación de las Reglas Provisorias de Justicia, básicamente el ABGB. austriaco había tenido vigencia. Por otro lado, debe tenerse presente que el código austriaco continuó en vigor en algunas partes de Hungría, por ejemplo, en el histórico Siebenbürgen. Ello debido a que ese sector, en virtud del Compromiso (en alemán: “Ausgleich”, en húngaro: “Kiegyezés”) del año 1867, permaneció bajo la administración central austriaca. La reiniciación de los trabajos preparatorios para la codificación del Derecho privado para la totalidad del territorio estatal húngaro debió esperar hasta el Compromiso austro-húngaro.

4. La Asamblea Nacional convocada el 10 de diciembre de 1865 resolvió comenzar con la elaboración de un Código Civil húngaro. En el año 1870, en el primer Congreso Nacional de Juristas de Hungría se propuso que entrara nuevamente en vigencia,

\footnotetext{
György Zsivora tuvo a su cargo altas funciones judiciales: en el año 1861 fue juez en la Tabula Septemviralis; entre 1869 y 1873 fue ministro presidente de la Curia Real (máximo tribunal en Hungría luego del compromiso austro-húngaro en el año 1867). Véase: TÓTH, L. Emlékbeszéd Zsivora György felett (Gedenkrede an György Zsivora) (Budapest, 1884).
} 
aunque en forma provisional, el Código Civil General austriaco. Por ese entonces fue resaltado, en especial por Imre Hódossy, que solamente era necesaria la reforma en un diez por ciento del texto de ese cuerpo legal. Otros, por el contrario, como Antal Rentmeister, seguidor de la Escuela Histórica del Derecho, hacían referencia a la importancia de conservar el antiguo Derecho patrio (ius patrium). Rezső dell'Adami acentuó que también el Tripartitum opus iuris consuetudinarii inclyti regni Hungariae, de István Werbőczy (ca. 1458-1541), considerado como Derecho patrio (en latín: ius patrium), había incluido muchos elementos extranjeros. Quien tomó significativamente la palabra como cuarta opción fue Sándor Daempf, al sostener la necesidad de elaborar un nuevo y autónomo Código Civil húngaro.

Luego de estos acontecimientos, el romanista y civilista húngaro, Pál Hoffmann (1830-1907), se dedicó a elaborar y trabajar en el año 1871 en el proyecto de la parte general del Código Civil húngaro (en húngaro: Általános Magánjogi Törvénykönyv). Ello le fue encomendado por el entonces ministro de justicia Boldizsár Horváth. El proyecto de Hoffmann sigue en esencia las secciones del Código Civil para el reino de Sajonia, publicado en 1863 y puesto en vigor en 1865, que reflejaba la influencia de Georg Friedrich Puchta. El proyecto fue informado por la Königliche Tafel (Tribunal Superior) y la Curia (Supremo Tribunal de Justicia): como crítica al mismo se resaltó su estilo complicado y el anacronismo de algunas instituciones jurídicas regulados. Un segundo proyecto de la parte general fue elaborado en el año 1880 por Elek Györy (1841-1902).

El próximo proyecto de codificación civil se limitó al Derecho sucesorio. En sus antecedentes se debe resaltar que en aquella área, los juristas húngaros tenían una posición especialmente conservadora. Esto se manifiesta ya en el Congreso Judiciario del año 1861 (la que decidió ampliamente el cese de vigencia del Código Civil General austriaco (ABGB) en Hungría), que conservaba la herencia linbeal ("paterna paternis, materna maternis"), esto es, la distinción entre bienes heredados y adquiridos en caso de inexistencia de sucesores, como así también la conservación del fideicomiso familiar (fideicommissum). Los participantes en el congreso fundamentaron esta decisión en la necesidad de "conservar el producto del genio jurídico creador del pueblo húngaro".

En el año 1871, en el Segundo Congreso Nacional de Juristas, llevado a cabo en la capital del País, István Teleszky (1836-1899) propuso codificar el Derecho sucesorio húngaro antes que toda la completa codificación; dos años más tarde fue designado por el ministro de Justicia para la preparación del correspondiente proyecto. En el año 1876, se publicó su obra bajo el título Örökösödési jogunk törvényhozási szabályozásához ("Sobre la técnica legislativa de nuestro Derecho sucesorio"), en el cual Teleszky dejó claramente expuestas sus ideas rectoras. Uno de sus puntos de reforma propuestos era derogar la institución feudal de la sucesión por generación (en húngaro: ági öröklés). El "Proyecto de un Código General Civil, Derecho sucesorio", oficialmente compuesto en 1882, se basaba 
en aquellos supuestos, así como, tanto en su estructura como en su contenido, igualmente en el Código Civil para el Reino de Sajonia (en alemán: Bürgerliches Gesetzbüch für das Königreich Sachsen) del año 1863/1865. Él también se inspiraba en el libro titulado: Entwurf eines deutschen Reichsgesetzes über das Erbrecht nebst Motiven (Braunschweig, 1876), de Friedrich Mommsen, una obra que también fue tomada en consideración en el conjunto de los trabajos preparatorios para la codificación del Derecho privado en Alemania iniciados en 1873. Este proyecto privado de Friedrich Mommsen influyó especialmente sobre las reglas relativas a las disposiciones de última voluntad y legados del proyecto de Teleszky. Además de ello, se debe resaltar que, contrariamente al Código Civil General austriaco, fundado en el principio de libertad testamentaria, en el caso del proyecto húngaro los sucesores legales gozaban de prelación. El proyecto de ley sobre Derecho sucesorio, publicado por la Comisión de Justicia del parlamento húngaro en el año 1889, seguía en todo al proyecto de Teleszky.

Al intento de codificación del Derecho de las obligaciones o de la relación obligacional, de István Apáthy² (1829-1889) - que, por lo demás, fue influido por el proyecto del Derecho de las obligaciones de Dresde, del año 1866, precedente del posterior Código Civil alemán (BGB.) - en la materia del negocio jurídico siguió la teoría de la voluntad ("Willenstheorie") de Savigny. Igual actitud asumió el proyecto de Pál Hoffmann y la "Parte general” (en alemán: “Allgemeiner Teil”, en húngaro: Általános Rész”) redactada por Elek Győry en 1880.

El proyecto sobre los derechos reales de Endre Halmossy, del año 1882, fue, por el contrario, influenciado en menor medida por la pandectística alemana.

Los proyectos en Derecho de familia de este período provienen de las obras de László Sipőcz (en alemán: Von der Vormundschaft und Pflegschaft, 1891), Benő Zsögöd (en alemán: Das persönliche Verhältnis der Ehegatten zueinander und eheliches Vermögensrecht, 1891) y Lajos Králik (en alemán: Von den Eltern und den Kindern, 1892).

El proyecto de Benő Zsögöd (Béni Grosschmid, 1852-1938) fue apenas influenciado por la pandectística alemana. Benő Zsögöd, en el área del dominio y del Derecho sucesorio, fue ante todo un comprometido representante del Derecho privado húngaro (ius patrium), de fuerte influencia feudal, y propugnador de su conservación.

En resumen, puede decirse que, con la ayuda de múltiples proyecto parciales, al inicio de los años de 1880, se consigue cierta inicial "textura", simple y al mismo tiempo defectuosa, de un primer proyecto completo del primer Código Civil. De todos modos, en el año 1894, la parte de las personas en materia de Derecho matrimonial fue legalmente

\footnotetext{
2 István Apáthy fue redactor de la primera ley húngara de derechos de autor (Ley 1884: XVI).
} 
regulada (Ley 1894: XXXI). También debe mencionarse la Ley 1877: XX sobre tutela y la curaduría.

5. La motivación y el impulso para que finalmente se sancionara un Código Civil dominó la política húngara desde 1895. Uno de los consecuentes seguidores de este movimiento, fue el romanista y civilista húngaro Gusztáv Szászy-Schwarz. Su proyecto de 2043 parágrafos fue totalmente concluido en el año 1900, mientras era ministro de Justicia el renombrado procesalista Sándor Plósz (1846-1925). Contrariamente a los anteriores proyectos parciales, este denominado primer proyecto puede calificarse como completo. En la estructura, como en las instituciones jurídicas, existe en forma evidente y clara una influencia del BGB. alemán. El proyecto consta de cuatro partes: personas y Derecho de familia, Derecho de las obligaciones, derechos reales y Derecho sucesorio. En este trabajo de codificación, las funciones de la faltante parte general son cubiertas por el primer título del Derecho de las obligaciones, el que es equivalente en todo caso a una parte general "oculta". En relación con el acto o negocio jurídico, el proyecto sigue la teoría de la declaración ("Erklärungstheorie").

El segundo proyecto de un Código Civil, del año 1913 (llamado "Texto de la Comisión del año 1913”), proviene del período en el cual ejerció funciones de ministro de Justicia Jenő Balogh, quien, lo mismo que su predecesor, Sándor Plósz, fue un renombrado jurista. En los párrafos de este corto proyecto de 1980 parágrafos, se nota una fuerte influencia del BGB. alemán como así también en el proyecto del año 1900. Igualmente este proyecto carece de una parte general y se estructura en los siguientes libros: personas y Derecho de familia, Derecho de las obligaciones, derechos reales y Derecho sucesorio. Así, desde el punto de vista de su estructura, no tiene ninguna diferencia con el primer proyecto del año 1900. Las corporaciones y fundaciones no son reguladas en este proyecto, sino que habrían que ser objeto de una ley especial. El proyecto presta especial atención a la protección de la transferencia y adquisición de buena fe, en tanto contiene modificaciones de carácter ético en comparación con el primer proyecto. El Derecho sucesorio es mucho más amplio y abarca más partes que el correspondiente proyecto que lo antecedió. Las principales innovaciones en Derecho sucesorio atañen al legado real, la administración de la masa sucesoria y la enajenación de la herencia.

En el año 1914 se publicó el tercer proyecto (denominado "Texto del Parlamento del año 1914”). En el año 1915 se publicó el cuarto proyecto (denominado "Proyecto de la Comisión del año 1915"). Ambos proyectos contienen sólo pequeñas modificaciones en relación con los proyectos de los años 1900 y 1913. El fracaso del tercer proyecto de Código Civil y del cuarto tuvo lugar ante todo debido a la Primera Guerra Mundial.

6. En la elaboración del quinto proyecto del Código de Derecho Privado (Magánjogi törvényjavaslat, abreviado como Mtj.), del año 1928, tuvo un sobresaliente 
desempeño Béla Szászy (1865-1931), llamado “el Eugen Huber húngaro”. ${ }^{3}$ El proyecto, compuesto por 2171 parágrafos, surge mientras ejercía el ministerio de Justicia András Tasnádi Nagy. Este proyecto de codificación del Derecho privado tiene un importante y fuerte influencia del Código Civil suizo (ZGB.), en especial de su Derecho de las obligaciones.

En relación con sus objetivos, la Pandectística alemana influyó en el Derecho privado húngaro en la responsabilidad independiente de la culpa o responsabilidad objetiva. En el proyecto del Código Civil húngaro del año 1900, se reguló la responsabilidad bajo la influencia del Código Civil alemán (BGB.), fundado en el principio de la culpa. El § 1486 del proyecto del año 1913, siguiendo al segundo proyecto (en alemán: “Zweiter Entwurf”) de Código Civil alemán del año 1887, regula el resarcimiento y responsabilidad por daños aún sin culpa (culpa). El internacionalmente conocido y ponderado $§ 1737$ del Proyecto de Código Civil (en forma abreviada: Mtj), del año 1928, que regula la responsabilidad por equidad, sigue, en lo esencial, aun cuando no en forma inmediata, al segundo proyecto (“Zweiter Entwurf”) de Código Civil alemán, en el cual se reconocía como regla subsidiaria la responsabilidad objetiva como fundamento del resarcimiento de daños.

En relación con la influencia del Mtj., debe destacarse que fue aplicado por los tribunales húngaros en el mismo nivel como Derecho vigente ("en tanto Derecho consuetudinario escrito"), debido a que el círculo de jueces lo describían con gusto como ratio scripta. Desde este punto de vista, puede reconocerse un gran paralelo entre el quinto proyecto (Mtj.) y el Tripartitum de István Werbőczy. Incluso muchos denominan al proyecto, y con razón, como la "carta constitucional del Derecho privado".

El enorme significado del intento de codificación se vio facilitado por una ley (Ley 1931: XXII), que dispuso y permitió la discusión parlamentaria del Mtj. para la sanción y promulgación del Código Civil. A los efectos de la coordinación en la promulgación, fue responsable el entonces ministro de Justicia Tibor Zsitvay (18841969). De acuerdo con esta ley, que regulaba el procedimiento parlamentario, se debía constituir una comisión de 60 miembros, de los cuales 30 debían ser parlamentarios de la cámara baja (en húngaro: “Képviselőház”) y de la alta (en húngaro: "Felsőház”). Es de destacar que en su discurso de apertura de las sesiones del parlamento, el regente (el entonces jefe de estado) de Miklós Horthy (1868-1957) resaltó que “el parlamento tenía

\footnotetext{
Béla Szászy, doctorado en la Universidad de Budapest en el año 1888, asumió una cátedra extraordinaria de Derecho eclesiástico e Historia del Derecho entre los años 1889-1892 en la Academia de Derecho de la Iglesia Reformada en Kecskemét. Entre los años 1892-1894 fue juez. A partir de 1894, trabajó en el Ministerio de Justicia. Béla Szászy fue desde 1918 director de la Sección de Elaboración de Leyes del Ministerio de Justicia húngaro, con el rango de secretario. En mayo de 1931 fue elegido como miembro correspondiente de la Academia Húngara de Ciencias. Véase: B. KOLOSVÁRY: Szászy Béla levelező tag emlékezete ["En memoria del miembro corresponsal Béla Szászy”]. (Budapest, 1934); también: K. SZLADITS, Szászy Béla (Budapest, 1934).
} 
una tarea que realizar poco frecuente en siglos". En este mismo año, la crisis económica conduce al cambio de gobierno, lo que produce por segunda vez el fracaso del intento de codificación.

El parlamento húngaro no sancionó el proyecto en el año 1931 por razones políticas coyunturales. Sin embargo, visto a largo plazo, fue decisivo que, luego de la Primera Guerra Mundial, de acuerdo al tratado de paz de Trianon de 4 de junio de 1920, una gran parte del territorio históricamente húngaro fue separado y anexado al territorio de los estados vecinos. Estos territorios debían ser excluidos en el período de guerra del sistema Derecho privado vigente con la sanción de un Código Civil húngaro. En estos territorios continuaba rigiendo en gran medida el Derecho consuetudinario húngaro no codificado. ${ }^{4}$ Una excepción a ello fue el estado de Burgenland, que se hallaba anexado a Austria, en donde el 15 de junio de 1922 entró en vigencia el Código Civil austriaco.

7. Como característica general de los cinco proyectos surgidos entre los años 1900 y 1928 puede establecerse lo siguiente: las significativas modificaciones en los proyectos, aún con el apoyo de la jurisprudencia húngara, no podían ser aceptadas por la deficiencia formal de una sanción parlamentaria de carácter oficial. Sin embargo, estas modificaciones condujeron a una especie de "fuente de leyes especiales del Derecho privado húngaro".

El legislador en efecto tomó de los proyectos el material para el trabajo legislativo y sanción de las posteriores leyes, entre otras, sobre responsabilidad en la compra de animales (Ley 1923: X), sobre la hipoteca (Ley 1927: XXXV), sobre Derecho de autor (Ley 1921: LIV) y también la responsabilidad en el hospedaje (Ley 1924: XIII).

8. El primer Código Civil húngaro fue sancionado en el año 1959 y rige actualmente, con modificaciones. La Comisión de Codificación fue convocada por el Consejo de Ministros en diciembre de 1953. Entre los miembros de la comisión se encontraban los representantes de las siguientes instituciones: las cátedras de Derecho civil de las tres facultades de Derecho de las universidades de Budapest, Pécs y Szeged, la cátedra de Derecho de la Universidad de Economía de Budapest, la sección de Derecho civil del Instituto de Estado y Ciencias Jurídicas de la Academia de Ciencias Húngara, el Superior Tribunal de Justicia y el fiscal superior como representante del Ministerio de Justicia.

El primer proyecto fue concluido en 1956. Luego de la primavera de 1957, los miembros de la comisión creada por el ministro de Justicia se ocuparon de los principales interrogantes del proyecto, dando lugar a uno modificado en el año 1957. Este proyecto fue publicado y sometido a la discusión pública. El texto del proyecto definitivo, que fue

\footnotetext{
4 También se debe aclarar que muchas partes del Derecho privado húngaro fueron reguladas por leyes especiales.
} 
realizado por una nueva comisión creada por el Ministerio de Justicia, fue presentado como proyecto de ley al parlamento y sancionado en el año 1959. El Código Civil húngaro (en alemán: “Zivilgesetzbuch”) entró en vigencia el 1 de mayo de 1960.

9. El Código Civil húngaror refleja, en su versión originaria, pese a la influencia fuerte de la ideología marxista (socialista), entre otros, la influencia del Código Civil suizo y Derecho de las obligaciones suizo, del Código Civil alemán y del Proyecto de Código Civil húngaro del año 1928 (Mtj). De los códigos civiles de los estados socialistas, los miembros de la comisión tuvieron en cuenta el Código Civil de la Rusia Soviética del año 1922, el Código Civil checoslovaco del año 1950, el Proyecto de Código Civil polaco del año 1955, La Ley sobre obligaciones y contratos búlgara del año 1950 y la Ley sobre propiedad búlgara del año 1951.

El Código Civil húngaro carece de una parte general (en alemán: Allgemeiner Teil); en su lugar se establecen disposiciones generales en siete parágrafos. El código está conformado por las siguientes partes: Disposiciones introductorias, Derecho de las personas (la persona natural como sujeto de Derecho, el Estado como sujeto de Derecho, la persona jurídica, la protección civil de las personas), propiedad (y de hecho los derechos reales), Derecho de las obligaciones, Derecho sucesorio y Disposiciones finales. En muchas instituciones jurídicas se refleja la influencia inmediata del Derecho romano.

El Código Civil húngaro no utiliza el concepto de derecho real (en húngaro: "dologi jog") ni la limitada noción de Derecho de las cosas. Igualmente, regula el contenido de las diferentes formas de propiedad (como la propiedad estatal, la propiedad de cooperativas, la denominada "propiedad personal" y, de forma muy limitada, lo vinculado con la existente propiedad privada), todo ello impregnado por lo desarrollado por Ulpiano con relación a los poderes del propietario (uti, frui, habere, possidere, abuti). En el área del Derecho de posesión, el Código Civil húngaro sólo conoce la possessio civilis, pero no la possessio naturalis (detentio). La protección de la posesión de ésta forma no estuvo inicialmente regulada en la ley, y sólo fue reconocida con posterioridad por la práctica jurisprudencial. Con relación a la transferencia de la propiedad, el Código Civil húngaro siguió el principio tradicional, es decir, paralelo a la causa (causa o titulus) es necesaria la entrega de la cosa (traditio). La prescripción adquisitiva (usucapio) no fue instituida según el Derecho romano, porque el Código Civil húngaro sólo exige como requisito una cosa susceptible de posesión (res habilis), pero no demanda buena fe (bona fides) ni una causa en tanto justo título (iustus titulus, iusta causa). Las servidumbres (servitutes) se reconocen como derechos autónomos de uso.

La parte correspondiente al Derecho de las obligaciones (parte IV) del Código Civil sigue el sistema de las Pandectas, en tanto contiene una parte general y otra especial. De la misma forma, y en ello es contrario al Código Civil alemán, se rechaza la distinción entre negocio jurídico unilateral y bilateral. En el Derecho de los 
contratos, los redactores del Código Civil húngaro siguieron a la teoría de la declaración. De acuerdo con la regula Catoniana, se puede solicitar irrestrictamente la nulidad de un contrato. El Derecho de prenda es regulado en tanto garantía de las obligaciones dentro del Derecho de las obligaciones, en tanto se reconoce el pignus Gordianum (Derecho de prenda para relaciones de tracto sucesivo y duraderas). Por influencia del Derecho romano, también se regulan las distintas obligaciones naturales (por ejemplo los créditos emanados de juegos y apuestas). Dentro del Derecho de las obligaciones (en el capítulo XXXV), también se regularon los contratos de plan (en húngaro: “tervszerződések"). Este capítulo, sin embargo, dejó de ser aplicado después de la reforma económica en el año 1968 (en húngaro: “új gazdasági mechanizmus" - "Nuevo mecanismo económico”) para ser finalmente derogada formalmente el año 1977.

El Derecho húngaro de sucesiones tiene sus raíces en el Derecho romano o tradición jurídica romana. El Código Civil húngaro conoce, sin embargo, sólo la sucesión ipso iure, y no considera -como, por ejemplo, lo hace el Código Civil General austríacola herencia yacente (hereditas iacens).

10. El Código Civil húngaro fue en poco tiempo, ya en los años 1967 y 1977 - ante todo por el cambio del sistema político-económico - impregnado de la ideología marxista (socialista) en sus disposiciones, quedando enfrentado con los requerimientos de la economía de mercado. Mientras algunas reformas del Código Civil húngaro modificaban su carácter fundamental (así, por ejemplo, la Ley 1991: XIV y la Ley 1993: XCII), otras innovaciones afectan sólo algunas instituciones jurídicas. En la Ley 1991: XIV se regularon la nulidad de los contratos contrarios a las buenas costumbres (contractus contra bonos mores) y se introdujo el principio de la buena fe. Desde el año 1996 existe la hipoteca sobre cosas muebles, lo que del mismo modo significa un retorno a la tradición jurídica romana.

El fenómeno de que el Código Civil húngaro del año 1959 -si bien con modificaciones- se haya adaptado tanto al fundamento jurídico de la "economía de mercado socialista" como también al sistema de economía de mercado, se explica porque sus redactores dieron mucho valor a los elementos constantes del Derecho civil -en manifiesto contraste, por ejemplo, con los redactores del Código civil (en alemán: Zivilgesetzbuch) de la República Democrática Alemana del año 1975- se dieron poca cabida a disposiciones impregnadas ideológicamente. De esta forma, se confirma en el Código Civil húngaro la tesis de Karl Renner sobre "la neutralidad del Derecho".

Incluso luego de la promulgación del Código Civil húngaro - en consonancia con la secularmente larga tradición húngara - la jurisprudencia, ante todo del Supremo Tribunal de Justicia (en húngaro: “Legfelsőbb Bíróság”), ha desempeñado un rol creador importante.

11. Varias partes del Derecho privado fueron codificadas, no en el Código 
civil húngaro sino en leyes especiales, en seguimiento del concepto socialista de las llamadas "ramas del Derecho". 5 El Derecho de familia fue regulado por la ley sobre matrimonio, familia y tutela del año 1952. Esta ley fue reformada varias veces incluso ante el cambio de sistema; así, por ejemplo, en el año 1987. El Código del Trabajo del año 1967 (el Derecho del trabajo fue regulado hasta entonces sólo a través de reglamentos) fue igualmente modificado varias veces hasta llegar a ser sustituido por un nuevo Código del Trabajo en el año 1992.

La “propiedad intelectual” se reguló inicialmente en una ley del año 1969, que fue luego sustituida por una nueva ley en 1999. El “decreto-ley”(en húngaro: “törvényerejü rendelet") sobre Derecho internacional privado proviene del año 1979 (decreto-ley nr. 13 de 1979). Las corporaciones se regulan en las leyes 1992:I y 2000:CXLI.

12. A lo largo de la elaboración ${ }^{6}$ de la nueva codificación del Derecho privado húngaro (Derecho civil, Derecho comercial, Derecho societario) se asumieron diferentes puntos de vista en relación con el Derecho societario (comercial): si debía ser regulado en forma independiente o integrado en la codificación. ${ }^{7}$ Esta discusión se vincula con la aceptación o rechazo de un Code unique.

El fundamento jurídico para una nueva codificación estatal integrada fue el Decreto del gobierno n. 1050/1998, luego modificado por otro, el n. 1061/1999. La Comisión Central de Codificación adoptó, en su sesión del 8 de noviembre del 2001, el "Proyecto del Nuevo Código Civil Húngaro " (en húngaro: Az új Polgári Törvénykönyv koncepciója). Con el Decreto del gobierno n. 1009/2002, el proyecto fue publicado el 31 de enero de 2002. ${ }^{8}$ Con el Decreto del gobierno n. 003/2003 se dio por terminada la elaboración de un texto legal concreto.

Como decisivo debe decirse que el nuevo Código Civil no representa un code unique -como, por ejemplo, podría serlo el Codice civile italiano del año 1942 o el nuevo Código Civil holandés (Nieuw Burgerlijk Wetboek) -. No contiene una parte general. El nuevo Código Civil húngaro tiene la siguiente estructura: Disposiciones introductorias (libro I), personas (libro II), Derecho de familia (libro III), derechos reales (libro IV), Derecho de las obligaciones (libro V), Derecho sucesorio (libro VI) y Disposiciones finales

\footnotetext{
Véase: HAMZA, G. A modern jogrendszerek tagozódása és a római jogi tradíció ("La ramificación de los ordenamientos jurídicos modernos y la tradición romanística”], en Állam-és Jogtudomány 40 (2004), p. 119.

6 En relación con el trasfondo teórico véase: VÉKÁS, L. Az új Polgári Törvénykönyv elméleti elökérdései ("Presupuestos teóricos para el nuevo Código Civil") (Budapest, 2001).

7 Véase: VÉKÁS, L. Szükség van-e kereskedelmi magánjogra? ["Es necesario un nuevo Derecho privado comercial"], en Magyar Jog 44 (1998), p. 705-714.

8 Véase: Magyar Közlöny ["Diario Oficial húngaro], 2002/15: Az új Polgári törvénykönyv koncepciója. Cfr. L. VÉKÁS, Az új Ptk. koncepciója és tematikája ["Concepto y temática del nuevo Código Civil húngaro"], en Magyar Közlöny különszám [“Edición especial del Diario Oficial húngaro”], Budapest, 10 de febrero del 2003.
} 
(libro VII). El proyecto de nuevo Código Civil húngaro en contraposición con el Código Civil del año 1959, regula también el Derecho de familia.

La Comisión Central de Codificación adoptó el concepto monista (concept moniste). En relación con el nuevo Código Civil húngaro rigen, por ejemplo, las disposiciones generales del Derecho de las obligaciones cuyas reglas son aplicadas en forma uniforme e indistinta a comerciantes y no comerciantes. Sin embargo, se aplican ciertas disposiciones especiales para los consumidores, en tanto los redactores incorporaron las nuevas corrientes en materia de Derecho europeo de la protección de consumidores. El concepto monista también tiene relevancia, ya que las reglas generales (Derecho privado) en relación con las sociedades comerciales se encuentran igualmente en el nuevo Código Civil húngaro (en la parte correspondiente a personas jurídicas). ${ }^{9}$

El Derecho del trabajo continúa siendo regulado en un código autónomo. En el Código Civil húngaro las reglas generales del Derecho de los contratos son aplicables en tanto materia jurídica singular, es decir, como fuente del contrato individual de trabajo.

Parte de la regulación concerniente a la "propiedad intelectual" (por ejemplo, los contratos de uso de elaboraciones intelectuales) son también incluidos en el nuevo Código Civil húngaro.

Los redactores no se orientaron por un único código civil extranjero; es por ello que, por ejemplo, el nuevo Código Civil holandés (Nieuw Burgerlijk Wetboek) no puede ser considerado como un único modelo. Los redactores tuvieron en cuenta, entre otras fuentes, la Convención de Viena sobre compraventa internacional, del año 1980, los principios Unidroit, los Principles of International Commercial Contracts del año 1994 y los Principles of European Contract Law, del año 1997. Los redactores consideraron también el Derecho privado comunitario, ${ }^{10}$ teniendo en cuenta la entrada de Hungría a la Unión Europea el primero de mayo del 2004.

La circunstancia de que Hungría, como único Estado reformista de Europa central y oriental, no haya sancionado una nueva constitución, por falta de un consenso político, no representa ningún obstáculo para el actual desarrollo de los trabajos de codificación. ${ }^{11}$

9 Véase: Szakértői javaslat az új Polgári Törvénykönyv tervezetéhez ["Propuesta de los expertos de un nuevo Código Civil para Hungría"] (Red. L. VÉKÁS) (Budapest, 2008).

${ }^{10}$ En relación con el concepto de la existencia del Derecho privado comunitario, en formación, véase una completa bibliografía en MÜLLER-GRAFF, P.-Chr., Privatrecht und europäisches Gemeinschaftsrecht. Gemeinschaftsprivatrecht (2. edición, Baden-Baden, 1991).

11 Una visión sobre los resultados actuales de la reforma del Derecho privado húngaro puede verse en un artículo de VÉKÁS, L. Über die umfangreiche Reform des ungarischen Zivilrechts., en Gedankenaustausch zwischen deutschen und ungarischen Juristen. Konferenzbeiträge 1997-2003 (Budapest, 2004), p. 418-432. Vékás es Presidente de la Comisión para la Nueva Codificación del Derecho Privado Húngaro. Sobre la reforma del Código Civil húngaro puede verse: Zeitschrift für Rechtsvergleichung, Internationales Privatrecht und Europarecht 45 (2004), p. 65-73. 
13. El Código Comercial húngaro, del año 1875, siguió el modelo del Código General de Comercio alemán (en alemán: Allgemeines Deutsches Handelsgesetzbuch, abreviado: ADHGB.), del año 1861. Vinculado con ello, el legislador húngaro siguió el sistema dualista (concept dualiste). Este concepto dualista no se ha modificado incluso, con el hecho de que Hungría sancionó su Código Civil recién en el año 1959. ${ }^{12}$ El Código de Comercio húngaro rigió, en su versión reformada, hasta fines de los años 40 , aunque sus reglas sobre sociedades comerciales permanecieron vigentes incluso hasta el primero de enero de 1989.

Una nueva ley de reforma sobre las "sociedades económicas" fue sancionada en Hungría en el año 1988, y entró en vigencia el 1 de enero de 1989 (Ley 1988: VI). Esta ley reemplazó el Código de Comercio húngaro y ha colaborado significativamente con el cambio económico del país. La novedosa Ley sobre sociedades económicas, del año 1997 (Ley 1997: CXLIV), fue derogada y reemplazada por una nueva ley el 1 de julio del año 2006 (Ley 2006: IV).

Hungría, mayo de 2008.

${ }^{12}$ En la doctrina también hay posiciones contrarias, según las cuales la codificación separada del Derecho comercial no tendría ningún sentido. Véase: GROSSCHMID, B., A kereskedelmi jognak különválásáról ["Sobre la separación del Derecho comercial"]; EL MISMO, Magánjogi tanulmányok (Budapest, 1901), p. 719-725. Grosschmid se fundamenta principalmente en el Derecho de las obligaciones para seguir el concepto monista. 